\title{
An organic coating pigmented with strontium aluminium polyphosphate for corrosion protection of zinc alloy coated steel
}

DOI:

10.1016/j.porgcoat.2016.02.020

\section{Document Version}

Accepted author manuscript

Link to publication record in Manchester Research Explorer

Citation for published version (APA):

Liu, Y., Zhou, X., Lyon, S. B., Emad, R., Hashimoto, T., Gholinia, A., Thompson, G. E., Graham, D., Gibbon, S. R., \& Francis, D. (2017). An organic coating pigmented with strontium aluminium polyphosphate for corrosion protection of zinc alloy coated steel. Progress in Organic Coatings, 102, 29-36.

https://doi.org/10.1016/j.porgcoat.2016.02.020

\section{Published in:}

Progress in Organic Coatings

\section{Citing this paper}

Please note that where the full-text provided on Manchester Research Explorer is the Author Accepted Manuscript or Proof version this may differ from the final Published version. If citing, it is advised that you check and use the publisher's definitive version.

\section{General rights}

Copyright and moral rights for the publications made accessible in the Research Explorer are retained by the authors and/or other copyright owners and it is a condition of accessing publications that users recognise and abide by the legal requirements associated with these rights.

\section{Takedown policy}

If you believe that this document breaches copyright please refer to the University of Manchester's Takedown Procedures [http://man.ac.uk/04Y6Bo] or contact uml.scholarlycommunications@manchester.ac.uk providing relevant details, so we can investigate your claim.

\section{OPEN ACCESS}




\title{
An Organic Coating Pigmented with Strontium Aluminium Polyphosphate for Corrosion Protection of Zinc Alloy Coated Steel
}

\author{
Yanwen Liu ${ }^{a^{*}}$, Xiaorong Zhou ${ }^{\mathrm{a}}$, Stuart B. Lyon ${ }^{\mathrm{a}}$, S.G.R. Emad ${ }^{\mathrm{a}}$, Teruo Hashimoto ${ }^{\mathrm{a}}$, Ali \\ Gholinia $^{\mathrm{a}}$, George E. Thompson ${ }^{\mathrm{a}}$, Derek Graham ${ }^{\mathrm{b}}$, Simon R. Gibbon ${ }^{\mathrm{b}}$, David Francis ${ }^{\mathrm{b}}$
}

${ }^{\mathrm{a} C}$ Corrosion and Protection Centre, School of Materials, The University of Manchester, Manchester M13 9PL, England, U.K.

${ }^{\mathrm{b}}$ AkzoNobel, Stoneygate Lane, Felling, Gateshead, NE10 0JY, England, U.K.

*Yanwen.Liu@Manchester.ac.uk

Tel: +44(0)1613065953

\begin{abstract}
An organic primer pigmented with strontium aluminium polyphosphate for the corrosion protection of zinc alloy coated steel was investigated by electron microscopy and electrochemical impedance spectroscopy after exposure to sodium chloride solution. The development of defects within the organic coating was found to be related to the solubility of the pigment, which resulted in two conflicting effects. On the one hand, the inhibitive species released from the solid pigment reduced the corrosion rate of the metal substrate by formation of precipitated products containing zinc, strontium, aluminium, phosphorus and oxygen. On the other hand, the dissolution of the inhibitive pigment resulted in porosity in the coating that created easy pathways not only for the inhibitors to reach the substrate but also for the aggressive species to
\end{abstract}


migrate inwards to the metal surface and, importantly, for the transport of corrosion products outwards.

Keywords: Strontium aluminium polyphosphate, inhibition, organic coating

\section{Introduction}

Organic coatings are widely used to protect metallic materials [1-3]. Such coatings provide barrier and active protection to the metal substrate mainly through the organic binder and inorganic pigments/fillers. The polymer binder and barrier fillers together contribute to the barrier protection of the metal substrate, while active protection is achieved by incorporation of corrosion inhibitive pigments [4-7]. Phosphate and polyphosphate inhibitive pigments, which are combined with one or more cations of zinc, calcium, aluminium, lithium, magnesium and strontium [8-22], are commonly used to replace traditional chromate-containing pigments that are environmentally hazardous and carcinogenic. These phosphate or polyphosphates pigments are assumed to be sparingly soluble in water but release free ions that protect the metal substrate at locations of coating damage by passivating the exposed metal or by otherwise forming a protective, precipitated, salt film. Hence, the solubility of corrosion inhibitive pigments plays a significant role in the protection of metal substrates. The low water solubility of the zinc phosphate pigment is suggested to be responsible for its relatively poor corrosion inhibition properties [17] in epoxy/polyamide coatings for protection of steel substrates. Zinc aluminium polyphosphate shows better corrosion inhibition properties compared with conventional zinc phosphate, which is attributed to an increased solubility [17]. Further, strontium aluminium polyphosphate has also revealed greater 
inhibitive properties again with increased water solubility [21, 23]. Strontium aluminium polyphosphates (SAPP) have been studied on steel substrates $[12,21,22$, 23] and are able to reduce the corrosion rate, assessed by electrochemical impedance and polarisation behaviour, both in solution extracts and in pigmented organic coatings.

Although the use of strontium aluminium polyphosphate has been studied on steel substrates, little information is available to date on applications for zinc and zinc-alloy coated coiled steel. In the present study, a model coil coating primer, comprised of a polyester binder and pigmented with strontium aluminium polyphosphate, applied on zinc alloy coated steel was studied using electrochemical impedance spectroscopy (EIS) and scanning electron microscopy (SEM). The measurement of impedance over a large frequency range provides information about various processes involved, including coating degradation and metal corrosion [24-28]. Such information was obtained by simulation of measured data using an equivalent circuit, in which coating properties are associated with high frequency circuit components, with coating damage and undercoating corrosion associated with low frequency impedance components. Further, electron microscopy together with energy dispersive X-ray analysis provides observation of the physical and chemical changes of the coated system during degradation. Thus, via EIS measurements of the coil coated system, and direct observation of organic primer degradation by SEM, the overall corrosion protection behaviour to the metal substrate by the primer coating pigmented with strontium aluminium polyphosphate inhibitor has been revealed.

\section{Experimental}


A model binder system was formed using a linear polyester resin (Dynapol LH 820-16 from Evonik) that was cross-linked with an aliphatic poly-isocyanate (Tolonate D2 from Perstorp). The binder was pigmented with a nominal fixed volume of $4.59 \mathrm{v} / \mathrm{v} \%$ titanium dioxide (from Kronos) $+0.41 \vee \%$ of hydrophilic fumed silica (from Aerosil), and $15 \mathrm{v} / \mathrm{v} \%$ of strontium aluminium polyphosphate (from Heubach). The model binder and pigments were mixed under high shear in a DAC $150.1 \mathrm{FVZ}$ speedmixer for at least 5 min, and the coating system was then applied to a metal substrate of zinc 5\% aluminium alloy coated (average $10 \mu \mathrm{m})$ steel $(800 \mu \mathrm{m}$ thick), with a roll bar coater to give a wet-film thickness of $24 \mu \mathrm{m}$. The coated steel panels were subsequently cured at a temperature of $300{ }^{\circ} \mathrm{C}$ for $1 \mathrm{~min}$ and then water quenched at room temperature. After curing, the average thickness of the coating was about $5 \mu \mathrm{m}$. The electrochemical impedance measurements were carried out using a three-electrode cell with a working electrode of exposed area $1.8 \times 2 \mathrm{~cm}$, a cylindrical platinum counter electrode and a saturated calomel reference electrode (SCE). The samples were exposed in $0.6 \mathrm{M} \mathrm{NaCl}$ solution, made from analytical grade chemicals and deionised water, held at room temperature. Impedance measurements were conducted at the free corrosion potential using a Gamry Reference 600 Potentiostat (Gamry Instrument), with a $10 \mathrm{mV}$ sine amplitude and a frequency range from $0.1 \mathrm{~Hz}$ to $10^{5} \mathrm{~Hz}$. Separate samples after immersion for 1, 7, and 57 days were rinsed in deionised water and dried in a cool air stream before SEM examination. Surface and cross sectional examinations of organic primer and zinc alloy coated steel before and after immersion in $0.6 \mathrm{M}$ sodium chloride solution were carried out by scanning electron microscopy (SEM) using a ZEISS Ultra 55 instrument with energy dispersive X-ray analysis (EDX) facilities and Quantum 3D 
FEGSEM with focused ion beam (FIB) facilities. The cross sections of the zinc alloy coated steel were also examined by transmission electron microscopy (TEM) using a JEOL FX 2000 II instrument operated at $120 \mathrm{kV}$, with a nominal sample thickness of 15 nm prepared by a Leica EM UC6 ultra-microtome with a diamond knife.

\section{Results}

\subsection{Electron microscopy examination}

The SAPP particles used as corrosion inhibitive pigments in the organic coating were examined by scanning electron microscopy (Fig. 1 a), which showed them to be of irregular shape and of varied dimensions, from 0.2 to $5 \mu \mathrm{m}$ across. EDX analysis indicated that the SAPP particles are likely to be a mixture of different chemical compounds, with the majority of the particles containing strontium, aluminium, oxygen, and phosphorus. The strontium to aluminium ratio ranged from 68:1 to about $0.3: 1$. Representative EDX spectra for a strontium-rich component and an aluminium-rich component are shown in Figs. 1 b and c. The zinc alloy coated steel surface before application of the organic coating was also examined by scanning electron microscopy, which revealed the presence of zinc primary phase, and the eutectic phase where the zinc-rich phase and the aluminium-rich phase are present in the same grain, as indicated in Fig. 2 a. A thin conversion oxide film, of about $50 \mathrm{~nm}$ thick, containing manganese, silicon, oxygen, and phosphorus was found by cross sectional examination of the zinc alloy employing transmission electron microscopy (Fig. 2 b) and EDX analysis. 
After organic coating had been applied, the surface of the zinc alloy coated steel did not appear smooth, with random distribution of protruded substances (Fig. 3 a). Cross sectional examination showed that these protrusions were associated with large sized SAPP pigment particles, or particle clusters, appearing as lighter regions in the organic primer of darker appearance (Fig. $3 \mathrm{~b}$ ). The organic primer, of $5 \mu \mathrm{m}$ average thickness, also contained fine, circular titanium dioxide particles, of 30-100 nm dimensions (Fig. 3 b). The conversion film beneath the organic primer in the cross sections was not readily observed by SEM due to the nano-scale thickness. Further, the cross sectional examination by SEM also showed that the zinc alloy layer had a rough surface profile, which resulted in the variation of local thickness, from 8-12 $\mu \mathrm{m}$ (Fig. 3 b). The interface between the zinc alloy coating and the steel substrate is also clearly revealed in Fig. 3 b.

The surface and cross section of zinc alloy coated steel with organic primer after immersion in $0.6 \mathrm{M} \mathrm{NaCl}$ for 1 day is displayed in Fig. 4. Most of the coating surface is similar to that before immersion (Fig. 4 a). Small cavities were evident in some locations, indicated by the arrows A and B in Fig. 4 a. These cavities coincided with protruded pigments, although not all protruded pigments developed cavities. Several locations with or without cavities were examined by sequential sectioning of the regions using ion beam. Fig. 4 b displays the cross section from the position indicated by a line in Fig. 4 a, which captured two protruded pigments, with one having developed a cavity (cavity A). It is revealed that cavity A was associated with the dissolution of a pigment particle in the organic primer (Fig. 4 b). EDX analyses showed that protruded pigments where cavities did not develop contained a high proportion of aluminium, while the 
residual pigment where cavity developed was rich in strontium, as displayed in Figs. $4 \mathrm{c}$ and $\mathrm{d}$ respectively.

For the coated sample after immersion in $0.6 \mathrm{M} \mathrm{NaCl}$ for 7 days, dark regions were developed at the periphery of the cavities (Figs. 5 a-b). Fig. 5 c shows a cross section of a large cavity beneath the surface of coated taken from the location indicated by the line A in Fig. 5 b, indicating a significant damage of the coating integrity in the region. After immersion for 57 days, significant damage of varied sizes was present on the coating (Figs. 6 a-b). Sequential cross sectioning of the damaged region in lines A and B of Fig. $6 \mathrm{~b}$ is displayed in Figs. $6 \mathrm{c}$ and d, which revealed that large particles, and particle clusters that connected through the thickness of the primer, had dissolved significantly. Corrosion of the zinc alloy was also observed beneath the primer coating (Figs. 6 c-d). EDX analysis in location $\mathrm{C}$ in Fig. $6 \mathrm{c}$ showed that the corrosion products that developed near the interface beneath the primer and the conversion film contained mainly zinc, aluminium, and oxygen, with low contents of strontium and phosphorus (Fig. 6 e). Further, the large cavities that resulted from the dissolution of the SAPP have been filled with zinc-containing corrosion products (Fig. 6 d). These cavity-filling corrosion products in the primer contain high levels of strontium and phosphorus, along with the zinc, aluminium and oxygen, as shown by EDX (Fig. 6 f).

\subsection{Electrochemical impedance spectroscopy evaluation}

The corrosion resistance of the zinc alloy coated steel with organic primer after immersion in $0.6 \mathrm{M} \mathrm{NaCl}$ was evaluated by electrochemical impedance spectroscopy 
(EIS). Selective impedance spectra at the beginning of immersion and after immersion for 1 day, 7 days, and 57 days, correlating to the samples examined by electron microscopy, are displayed in Fig. 7, with circular, square, triangular and cross markers representing the measured values of EIS spectra immediately on immersion, after 1 day, after 7 days, and after 57 days immersion respectively. The solid lines are the fitted simulation data, which will be explained further.

Interpretation of the impedance spectra was made by fitting the data using equivalent circuits. The proposed circuits after different immersion times are shown in Figs. 8 a-d, which represent the undamaged primer coated sample (Fig. 8 a) at the beginning of immersion, initial dissolution of the inhibitor after 1 day (Fig. 8 b), significant dissolution of the inhibitor and revealing the resistance from conversion film after 7 days (Fig. 8 c), and the damage to both primer and conversion film (Fig. 8 d) after prolonged immersion of 57 days. Detailed fitting values are listed in Table 1. Here the capacitances used in the model were replaced by constant phase elements (CPE), which are indications of the imperfection of the capacitances. The elements used for the fitting and simulation include solution resistance $\left(\mathrm{R}_{\mathrm{s}}\right)$, non-ideal primer coating capacitance $\left(\mathrm{CPE}_{\text {primer }}\right)$, initial primer coating resistance $\mathrm{R}_{\text {primer }}$, primer coating resistance in the presence of flaws ( $R_{\text {pore }}$, the ionic resistance through defects or pores in the coating), non-ideal conversion film capacitance $\left(\mathrm{CPE}_{\text {film }}\right)$, conversion film resistance $\left(\mathrm{R}_{\text {film }}\right)$, nonideal capacitance of double layer $\left(\mathrm{CPE}_{\mathrm{dl}}\right)$, charge transfer resistance $\left(\mathrm{R}_{\mathrm{ct}}\right.$ which is related to the Faradic reaction), and Warburg resistance which controlled mass transfer of diffusion species. 
From the Bode plot of the impedance modulus (Figure 7 a), it is evident that an immediate measurement of impedance after immersion in $0.6 \mathrm{M} \mathrm{NaCl}$ revealed a high impedance in the order of $10^{8} \mathrm{ohm} \mathrm{cm}^{2}$ at the low frequency of $0.1 \mathrm{~Hz}$, with the Bode phase diagram showed a broadening of the phase range from $10^{5}$ to $1 \mathrm{~Hz}$ at angles greater than $80^{\circ}$, indicating a very good barrier provided by the organic primer (Fig. 7 b). The spectrum was well represented by a parallel circuit of low CPE with a high resistance (Fig. 8 a), as shown with solid lines in in Fig. 7 a and b, as well as in Table 1, indicating the initial primer coating provided a very good barrier protection to the zinc alloy coated steel.

After 1 day of immersion, the impedance magnitude decreased to the order of $10^{6} \mathrm{ohm}$ $\mathrm{cm}^{2}$ at the low frequency of $0.1 \mathrm{~Hz}$ (Figure $7 \mathrm{a}$ ), accompanied by the reduction of the frequency range for high phase angle (now from $10^{5}$ to $10^{2} \mathrm{~Hz}$ ), indicating a significant reduction of coating resistance due to damage of the barrier developed in the organic primer (Fig. 7 b). The EIS spectrum showed a single time constant with a tail from the Bode-phase plot, which can be fitted with the equivalent circuit of Fig. 8 b, which simulated the property of primer coating with $\mathrm{CPE}_{\text {primer }}$ and $\mathrm{R}_{\text {pore }}$. The tail of the spectrum can be considered to represent the impedance from the conversion film and under-film corrosion and can be represented with a Warburg resistance, as shown in Fig. $8 \mathrm{~b}$.

After 7 days of immersion, the impedance modulus at low frequency of $0.1 \mathrm{~Hz}$ was close to the order of $10^{5} \mathrm{ohm} \mathrm{cm}^{2}$ and the phase started to drop at the beginning of high frequency, indicating that the barrier protection from organic primer was significantly 
damaged. A second time constant, from $300 \mathrm{~Hz}$ may be derived from the resistance of the conversion film on zinc alloy surface, as observed from Fig. 1 b. Such a film showed a relatively good corrosion resistance at the immersion time of 7 days, as the phase angle was sustained and slightly increased at the value above $25^{\circ}$ at low frequency range below $10 \mathrm{~Hz}$. The equivalent circuit for such a process is represented in Fig. 8 c, which showed a significant reduction of resistance from the primer coating. In this stage, the conversion film played a significant role in the corrosion protection of the zinc alloy coated steel.

After immersion for 57 days, the impedance modulus at low frequency was in the order

of $10^{4} \mathrm{ohm} \mathrm{cm}^{2}$ and a third time constant was observed at the low frequency between 10 to $0.1 \mathrm{~Hz}$. The fitting of the data with the equivalent circuit in Fig. $8 \mathrm{~d}$ revealed that both the primer coating and the conversion film suffered from significant damage to the barrier protection of the zinc alloy surface. The remaining CPE value for the conversion film in this stage may be partially contributed by the formation of a mixture of corrosion products with SAPP inhibitor beneath the conversion film at the metal/film interface, as evident in Figs. 6 c and d. Although charge transfer resistance is in the order of $10^{4} \Omega$, the corrosion protection of zinc alloy coated steel is mainly offered by the reaction of dissolved corrosion inhibitor with corrosion products.

\section{Discussion}

The combined electrochemical evaluation and microscopic observation has advanced the understanding of the degradation process of the organic primer coating and the 
protection to the zinc alloy offered by coatings and SAPP inhibitor when exposed in 0.6 $\mathrm{M} \mathrm{NaCl}$ solution.

The dissolution of SAPP in the primer coating resulted in the reduction of barrier protection to zinc alloy coated steel, evident by the reduction of impedance during the first day of immersion. Simulation of the impedance showed the increase of $\mathrm{CPE}_{\text {primer }}$ was accompanied by the reduction of $\mathrm{R}_{\text {pore, }}$, which can be correlated to the observation of the through-thickness cavity formation during dissolution of SAPP pigments. Further, the substantial dissolution of SAPP pigment in the primer coating provided easy route for the electrolytes to access the metal surface through the primer coating after 7 days. In this stage, the original conversion film on the zinc alloy played a significant role in the protection of zinc alloy coated steel, which was revealed by the relatively low $\mathrm{CPE}$ value and high corrosion resistance. The combination of the deterioration of primer coating and conversion film resulted in the corrosion of zinc alloy, as observed by SEM after a prolonged immersion time of 57 days. At this stage, the dissolved SAPP inhibitor in the solution played a role in the inhibition of the zinc alloy corrosion, as evident by the value of charge transfer resistance from the EIS spectrum measured after immersion of the sample in $0.6 \mathrm{M} \mathrm{NaCl}$ for 57 days. This "secondary" corrosion protection was achieved by the formation of solid corrosion products precipitated on the zinc alloy surface that then extruded outwards and filled the cavities left by the dissolution of SAPP pigment in the primer coating as evidenced by EDX analyses at the locations. Large cavities and connected porosities not only played a role in delivering the corrosion inhibitor, but also provide preferential routes for the 
electrolytes to reach the metal surface and for the movement of corrosion products outwards from the surface of the primer coating.

Finally, it appears that the strontium to aluminium molar ratio may control the release of the corrosion inhibitor. Thus, higher strontium to aluminium molar ratios resulted in greater cavity formation (i.e. faster release of the SAPP inhibitor), while few or no cavities were evident with SAPP of low strontium to aluminium molar ratio.

\section{Concluding remarks}

The dissolution/leaching of strontium aluminium polyphosphate resulted in two conflicting effects on the corrosion protection of the organic primer on the zinc alloy coated steel. On the one hand, the dissolution of the corrosion inhibitive pigment disrupted the integrity of the coating. Consequently, large cavities and connected porosity network generated by the dissolution of the corrosion inhibitive pigment provide easy pathways for the aggressive species to reach the substrate. On the other hand, the dissolved SAPP delivered active protection to the zinc alloy, which retarded the corrosion. Further, insoluble corrosion product, or precipitated inhibitive salt film, appears to form by the reaction of the zinc alloy and the SAPP, which evidently filled the cavities left by the dissolution of SAPP, consequently, providing barrier protection to the metal substrate.

\section{Acknowledgments}


The authors wish to thank AkzoNobel for sponsoring this work.

\section{References}

[1] R.P. Edavan, R. Kopinski, Corrosion resistance of painted zinc alloy coated steels, Corrosion Science 51 (2009) 2429-2442.

[2] B.M. Rosales, A.R. Di Sarli, O.de Rincón, A. Rincón, C.I. Elsner, B. Marchisio, An evaluation of coil coating formulations in marine environments, Progress in Organic Coatings 50 (2004) 105-114.

[3] P. Puomi, H. Fagerholm, Characterization of hot-dip galvanized (HDG) steel treated with $\gamma$-UPS, VS, and tetrasulfide, J. Adhesion Sci. Technol. 15 (2001) 509-533.

[4] Y. Liu, P. Visser, X. Zhou, S.B. Lyon, T. Hashimoto, M. Curioni, A. Gholinia, G.E. Thompson, G. Smyth, S.R. Gibbon, D. Graham, J.M.C. Mol, and H. Terryn, Protective Film Formation on AA2024-T3 Aluminum Alloy by Leaching of Lithium Carbonate from an Organic Coating, Journal of The Electrochemical Society 163 (2016) C45-C53.

[5] P. Visser, Y. Liu, X. Zhou, T. Hashimoto, G.E. Thompson, S.B. Lyon, L.G.J. van der Ven, A.J.M.C. Mol and H.A. Terryn, The corrosion protection of AA2024-T3 aluminium alloy by leaching of lithium containing salts from organic coatings, Faraday Discussions 180 (2015) 511-526.

[6] Y. Liu, P. Visser, X. Zhou, S.B. Lyon, T. Hashimoto, A. Gholinia, G.E. Thompson, G. Smyth, S.R. Gibbon, D. Graham, J.M.C. Mol and H. Terryn, An investigation of the corrosion inhibitive layers generated from lithium oxalate containing organic coating on AA2024-T3 aluminium alloy, Surface and Interface Analysis, accepted. 
[7] P. Visser, Y. Liu, H.Terryn, J.M.C. Mol, Lithium-salts as leachable corrosion inhibitors and potential replacement for hexavalent chromium in organic coatings for the protection of aluminium alloys, Accepted by Journal of Coatings Technology and Research DOI:10.1007/s11998-016-9784-6.

[8] I.M. Zin, V.I. Pokhmurskii, J. D. Scantlebury, and S. B. Lyon, Model electrochemical cell study of cut-edge corrosion inhibition on coil-coated steel sheet by chromate-, phosphate-, and calcium-containing pigments, Journal of The Electrochemical Society 148 (2001) B293-B298.

[9] R. Naderi, M.M. Attar, Application of the electrochemical noise method to evaluate the effectiveness of modification of zinc phosphate anticorrosion pigment, Corrosion Science 51 (2009) 1671-1674.

[10] A.M. Simões, J. Torres, R. Picciochi, J.C.S. Fernandes, Corrosion inhibition at galvanized steel cut edges by phosphate pigments, Electrochimica Acta 54 (2009) 38573865.

[11] Y. Hao, F. Liu, E Han, S. Anjum, G. Xu, The mechanism of inhibition by zinc phosphate in an epoxy coating, Corrosion Science 69 (2013) 77-86.

[12] Y. Shao, C. Jia, G. Meng, T. Zhang, F. Wang, The role of a zinc phosphate pigment in the corrosion of scratched epoxy-coated steel, Corrosion Science 51 (2009) 371-379.

[13] V.F. Vetere, M.C. Deya, R. Romagnoli, and B. del Amo, Calcium tripolyphosphate: an anticorrosive pigment for paint, Journal of Coatings Technology 73 (2001) 57-63.

[14] M.R. Heydarpour, A. Zarrabi, M.M. Attar, B. Ramezanzadeh, Studying the corrosion protection properties of an epoxy coatingcontaining different mixtures of 
strontium aluminum polyphosphate(SAPP) and zinc aluminum phosphate (ZPA) pigments, Progress in Organic Coatings 77 (2014) 160-167.

[15] R. Naderi, M.M. Attar, Electrochemical assessing corrosion inhibiting effects of zinc aluminum polyphosphate (ZAPP) as a modified zinc phosphate pigment, Electrochimica Acta 53 (2008) 5692-5696.

[16] A. Kalendova, Comparison of the anticorrosion efficiencies of pigments based on condensed phosphates and polyphosphosilicates, Anti-Corrosion Methods and Materials 50 (2003) 82-91.

[17] R. Naderi, M.M. Attar, Electrochemical study of protective behavior of organic coating pigmented with zinc aluminum polyphosphate as a modified zinc phosphate at different pigment volume concentrations, Progress in Organic Coatings 66 (2009) 314320.

[18] E. Alibakhshi, E. Ghasemi, M. Mahdavian, Corrosion inhibition by lithium zinc phosphate pigment, Corrosion Science 77 (2013) 222-229.

[19] R. Naderi, M.M. Attar, The role of zinc aluminum phosphate anticorrosive pigment in Protective Performance and cathodic disbondment of epoxy coating, Corrosion Science 52 (2010) 1291-1296.

[20] Y.F. Yang, J.D.Scantlebury, E. Koroleva, O. Ogawa, H. Tanabe, A novel anticorrosion calcium magnesium polyphosphate pigment and its performance in aqueous solutions on mild steel, ECS Transactions 24 (2010) 77-85.

[21] R. Naderi, M. Mahdavian, A. Darvish, Electrochemical examining behavior of epoxy coating incorporating zinc-free phosphate-based anticorrosion pigment, Progress in Organic Coatings 76 (2013) 302-306. 
[22] C. Deyá, G. Blustein, B. del Amo, R. Romagnoli, Evaluation of eco-friendly anticorrosive pigments for paints in service conditions, Progress in Organic Coatings 69 (2010) 1-6.

[23] R. Naderi, M.M. Attar, The inhibitive performance of polyphosphate-based anticorrosion pigments using electrochemical techniques, Dyes and Pigments 80 (2009) 349-354.

[24] J.N. Murray, Electrochemical test methods for evaluating organic coatings on metals: an update. Part III: Multiple test parameter measurements, Progress in Organic Coatings 31 (1997) 375-391.

[25] G.W. Walter, A review of impedance plot methods used for corrosion performance analysis of painted metals, Corrosion Science 26 (1986) 681-703.

[26] A. Meroufel, S. Touzain, EIS characterisation of new zinc-rich powder coatings, Progress in Organic Coatings 59 (2007) 197-205.

[27] J.N. Murray, Time constraints in the testing of salt-fogged samples via electrochemical impedance spectroscopy, Progress in Organic Coatings 49 (2004) 342352.

[28] A.R. Marder, The metallurgy of zinc-coated steel, Progress in Materials Science 45 (2000) 191-271.

\section{Figure captions}

Fig. 1. (a) a scanning electron micrograph of SAPP inhibitive pigment; (b) EDX analysis of strontium-rich SAPP pigment; (c) EDX analysis of aluminium-rich SAPP pigment. 
Fig. 2. (a) a scanning electron micrograph of the surface of zinc alloy coated steel; (b) a transmission electron micrograph of the cross section of the conversion film formed on zinc alloy surface.

Fig. 3. Scanning electron micrographs of the organic primer coating on zinc alloy coated steel before exposure to sodium chloride solution: (a) the surface of the organic primer coated alloy; (b) the cross sectional examination, showing three distinct layers, i.e. organic primer, zinc alloy, and steel substrate.

Fig. 4. Scanning electron micrographs of the organic primer coated alloy after immersion in $0.6 \mathrm{M} \mathrm{NaCl}$ for 1 day: (a) surface of the primer coated alloy, the majority of the surface appearance of the coating is similar to the surface before immersion with small damaged areas; (b) cross sectional examination of the sample, revealing the dissolution of SAPP particle in the primer coating; (c) EDX analysis of un-dissolved SAPP particle, rich in aluminium; (d) EDX analysis of the residual SAPP particle after dissolution, rich in strontium.

Fig. 5. The surface and the cross section of the organic primer coated alloy after immersion in $0.6 \mathrm{M} \mathrm{NaCl}$ for 7 days: (a) and (b) deposits were observed on the surface; (c) large cavities were revealed in the organic primer.

Fig. 6 The surface and the cross section of the sample after immersion in $0.6 \mathrm{M} \mathrm{NaCl}$ for 57 days: (a) and (b) significant stains were observed on the surface; (c) the 
dissolution of connected SAPP particle clusters which extend from the surface to the zinc alloy substrate, with corrosion also observed in the zinc alloy near interface; (d) corrosion products which filled the location in the primer coating where strontium aluminium polyphosphate inhibitor was left: (e) EDX analysis revealing the presence of small amount of strontium and phosphorus species along with zinc, aluminium and oxygen in the corrosion products developed near interface; (f) EDX analysis showing the presence of Zinc, oxygen, strontium, aluminium, and phosphorus species in the corrosion products formed in the organic coating, which filled the cavities where SAPP had dissolved.

Fig. 7. (a) Bode magnitude and (b) phase plots of electrochemical impedance spectra, and simulated fitting data for the organic primer coated alloy at the beginning of immersion or after immersion for 1 day, 7 days, and 57 days immersion in $0.6 \mathrm{M} \mathrm{NaCl}$ solution.

Fig. 8. Equivalent circuit used to simulate measured impedance data: (a) at the beginning of immersion; (b) after immersion for 1 day; (c) after immersion for 7 days; and (d) after immersion for 57 days. 
Table 1. Values for the components used in equivalent circuits for fitting of the measured EIS spectra

\begin{tabular}{|c|c|c|c|c|}
\hline & Immediate & After 1 day & After 7 days & After 57 days \\
\hline Rs ohm cm ${ }^{2}$ & 10 & 10 & 10 & 10 \\
\hline $\mathrm{CPE}_{\text {primer }}-\mathrm{T}\left(\mathrm{F} \mathrm{cm}^{-2} \mathrm{~s}^{\mathrm{n}-1}\right)$ & $2.45 \mathrm{E}-09$ & $3.557 \mathrm{E}-09$ & $6.02 \mathrm{E}-09$ & $9.30 \mathrm{E}-09$ \\
\hline n-primer & 0.97 & 0.96 & 0.93 & 0.93 \\
\hline $\mathrm{R}_{\text {primer }}\left(\Omega \mathrm{cm}^{2}\right)$ & $2.34 \mathrm{E}+09$ & & & \\
\hline $\mathrm{R}_{\text {pore }}\left(\Omega \mathrm{cm}^{2}\right)$ & & $4.03 E+06$ & 10714 & 478.7 \\
\hline $\mathrm{CPE}_{\text {film }}\left(\mathrm{F} \mathrm{cm}^{-2} \mathrm{~s}^{\mathrm{n}-1}\right)$ & & & 3.63E-07 & $9.10 \mathrm{E}-07$ \\
\hline$n$-film & & & 0.81 & 0.66 \\
\hline$R_{\text {film }}\left(\Omega \mathrm{cm}^{2}\right)$ & & & 5350 & 1839 \\
\hline $\mathrm{CPE}_{\mathrm{dl}}\left(\mathrm{F} \mathrm{cm}^{-2} \mathrm{~s}^{\mathrm{n}-1}\right)$ & & & $2.29 \mathrm{E}-06$ & $7.69 \mathrm{E}-05$ \\
\hline$n-\mathrm{dl}$ & & & 0.75 & 0.66 \\
\hline $\mathrm{R}_{\mathrm{ct}}\left(\Omega \mathrm{cm}^{2}\right)$ & & & 26125 & 10230 \\
\hline Ws-R $\left(\Omega \mathrm{cm}^{2}\right)$ & & $1.50 \mathrm{E}+07$ & 423780 & \\
\hline Ws-T $\left(\mathrm{s}^{-1}\right)$ & & 139.2 & 80.95 & \\
\hline Ws-n & & 0.32 & 0.47 & \\
\hline
\end{tabular}

